\title{
Supplemental and Synchronized Pollination May Increase Yield in Cacao
}

\author{
Samantha Jay Forbes \\ College of Science and Engineering, James Cook University, Cairns, \\ Queensland, Australia
}

Guiliana Mustiga and Alberto Romero

Mars, Inc., c/o USDA-ARS Subtropical Horticulture Research Station, 13601

Old Cutler Road, Miami, FL 33158

\section{Tobin David Northfield}

College of Science and Engineering, James Cook University, Cairns, Queensland, Australia; and Tree Fruit Research and Extension Center, Washington State University, Wenatchee, WA 98801

\section{Smilja Lambert}

Mars, Inc., Jln Kima 10, Kav. A6, Kima, Makassar, South Sulawesi, Indonesia

\section{Juan Carlos Motamayor \\ Mars, Inc., c/o USDA-ARS Subtropical Horticulture Research Station, 13601 Old Cutler Road, Miami, FL 33158}

Additional index words. cherelle wilt, cocoa, dominance, fruit set, artificial pollination, resource competition, Theobroma cacao

\begin{abstract}
Artificial pollination management strategies are a potential solution to improving the livelihoods of smallholder cacao farmers by increasing crop productivity in situations when pollination services are limiting. However, field-based research trials evaluating the yield benefits of artificial pollination management strategies within intensified cacao systems are lacking. Thus, in an intensively managed cacao system, we evaluated the effects of artificial pollination condition (i.e., pollen genotype, pollination intensity, and pollination synchrony) on fruit development and yield in three high-yielding cacao clones. Artificial pollination, regardless of intensity, significantly increased fruit set and yield. Pollination synchrony had a significant effect on cherelle survivorship; older cherelles had greater survival rates across all developmental stages than younger cherelles. Yield differed between genotype crosses and varied according to the pollen donor used, highlighting the importance of understanding self- and cross-compatibility when selecting clones for cultivation. Pollination intensity had no significant effect on harvested yield, indicating that more rigorous research is needed to identify the pollination intensity required for optimized yield under artificial pollination conditions. We conclude that strategies to enhance flowering, pollination rates, and pollination synchrony while ensuring adequate tree nutrition may increase productivity in cacao. Future research evaluating numerous cacao clones across multiple years and locations may help us to understand the region-specific effects of intensive management strategies on the long-term sustainability of enhancing cacao tree productivity.
\end{abstract}

Cacao is a neotropical species originating in the lowland rainforests of South America (Motamayor et al., 2002) that develops large pods (fruit), each containing an average of 30 to 40 seeds (Lima et al., 2011). After they

Received for publication 27 Feb. 2018. Accepted for publication 10 Apr. 2019.

We thank Tamsil Hidayat, Achmad Ferdiansyah, Nirwana, and Team Pollinasi at the Mars Cocoa Research Centre for assisting with fieldwork. We also thank Mars Inc. for funding the research. J.C.M. is the corresponding author. E-mail: ajuan. motamayor1@effem.com. monoculture cacao plantations managed using high inputs of agrochemicals, irrigation, and mechanization. Cacao intensification has also included genetic advances such as the development of high-yielding and diseaseresistant cacao cultivars to increase yield production (Edwin and Masters, 2005; Motamayor et al., 2013; Vaast and Somarriba, 2014). However, in field settings where cacao trees are exposed to variable environmental conditions, selectively bred traits to increase yield (e.g., increases in the number and size of pods per tree and seeds per pod) (Cilas et al., 2010) may not be fully realized or may be antagonistic.

Field-based research on increasing cacao yields in intensified cultivation systems is rare (but see Bos et al., 2007; Carr and Lockwood, 2011; De Almeida and Valle, 2007; Goenaga et al., 2009, 2015; Johns, 1999; Zuidema et al., 2005). Furthermore, field trials evaluating the yield of advanced cacao clones under optimal management practices (e.g., fertigation) across multiple locations are not uniformly established. As a result, current yield potential estimations of advanced cacao clones (e.g., Aneani and Ofori-Frimpong, 2013; Bos et al., 2007; Falque et al., 1995, 1996; Goenaga et al., 2009, 2015; Groeneveld et al., 2010) are highly variable and there is a pressing need to evaluate further the yield-limiting factors for numerous clones under intensified management conditions.

Cacao produces a surplus of flowers, with possibly up to 125,000 flowers per tree per year (Lachenaud and Mossu, 1985). However, low fruit: flower ratios are still observed in most producing areas (Aneani and OforiFrimpong, 2013). No more than $10 \%$ of the flowers produced are naturally pollinated (Groeneveld et al., 2010) and even fewer $(0.5 \%$ to $5 \%)$ develop into mature pods under open pollination conditions, primarily because of fruit abortion (Bos et al., 2007; De Almeida and Valle, 2007; Falque et al., 1995; Young and Severson, 1994). Consequently, pollination and resource availability are widely accepted as two major extrinsic factors limiting cacao production (e.g., Ayre and Whelan, 1989; Bos et al., 2007; Brown and McNeil, 2006; Falque et al., 1995; Groeneveld et al., 2010; Valle et al., 1990; Young, 1982; Young and Severson, 1994; Zuidema et al., 2005).

Although it is well known that most cacao varieties are self-incompatible (Falque et al., 1996), very little is known about pollination services or pollinator ecology in cacao (Toledo-Hernandez et al., 2017). The general consensus suggests that cacao trees strongly depend on the cross-pollination services provided by ceratopogonid midges (Ceratopogonidae) (Kaufmann, 1975; Posnette, 1944; Winder, 1978; Young, 1982). However, low natural midge abundance in cacao systems is widely reported (Winder, 1978), which may drive down pollination rates and limit cacao yield increases (Forbes and Northfield, 2016; Frimpong et al., 2009; Young, 1982; Young and Severson, 1994). In support of pollination limitation, Groeneveld et al. (2010) —in 
a low-input agricultural cacao cultivation system - found a significant increase in cacao yield when artificially increasing pollination rates from $10 \%$ to $40 \%$ of flowers pollinated, despite increases in relative fruit abortion. However, Valle et al. (1990) concluded that fruit abortion (cherelle wilt), rather than manipulated pollination rates, was the major factor limiting yield, resulting from variations in fruit-bearing capacity and resource availability.

These results suggest that the upper limit to cacao yield is ultimately set by the number of flowers produced (flowering intensity) (Falque et al., 1995), the number of flowers successfully pollinated (pollination intensity) (Groeneveld et al., 2010), and the resources available to support the developing fruit (Valle et al., 1990). At increased pollination levels, the energetic cost of producing a large number of pods is high (Groeneveld et al., 2010), which may lead to yield reductions via increases in relative cherelle wilt, particularly if resources are limiting (Bos et al., 2007; Valle et al., 1990).

Previous research suggests that the incidence of cherelle wilt may be influenced by the timing of pollinations (pollination synchrony), under the assumption that pods of the same developmental age should not compete strongly with each other until they are no longer susceptible to wilt (i.e., until after 100 d) (Hutcheon, 1977). Therefore, synchronizing pollination efforts into a concentrated time frame may increase the pod production of cacao trees by reducing competitive hierarchy (i.e., reduced competition between pods of different ages) during the wilting stages. However, increases in the pertree pod number after $100 \mathrm{~d}$ may compromise pod size and quality at harvest, resulting from the substantially increased resource requirements of pods during this stage of development (Hutcheon, 1977). Synchronized pollination can increase kernel set in maize (Zea mays L.) (Carcova and Otegui, 2001; Carcova et al., 2000; Sarquis et al., 1998), suggesting a negative impact of increasing the interval time between pollinations. However, to date, no research has addressed the potential consequences of altering the natural synchrony of pollination through artificial pollination on cacao yields when nutrients are nonlimiting.

Together, the previous findings suggest that the pollination and resource conditions required for maximizing the pod carrying capacity of an individual cacao tree are unlikely to be fixed. Rather, a spatiotemporal interplay between flower production, pollination intensity, pollination synchrony, genotype compatibility, resource availability, and the genetically predisposed physiological ability of the maternal tree to meet resource demands may be underlying cacao yield potential. Understanding the effects of potential pollination condition (i.e., pollen genotype, pollination intensity, and pollination synchrony) interactions on fruit set, cherelle wilt, and final yield may have large impacts on cacao management and production profit- ability. Thus, we aimed to identify the pollination conditions required for increased yield in three high-yielding cacao clones within an intensively managed cacao cultivation system in which the nutritional requirements for pod production are presumably met. We pollinated artificially a predetermined percentage of open flowers present on a tree on a given day and examined the effects of 1) pollen donor genotype, 2) pollination intensity, and 3) pollination synchrony on the survivorship of pollinated flowers to harvested pods.

\section{Materials and Methods}

We present a series of experiments - trial 1 and trial 2-that were carried out to address the research aims detailed earlier. Trial 1 evaluated the effects of artificial pollination and maternal and paternal genotype cross on harvested yield in cacao. This trial was conducted using two successive subtrials, hereafter referred to as trial 1.1 and trial 1.2 , which differed by the paternal pollen donor used for artificial pollination as well as the trial timing (season). Trial 2 evaluated the effects of pollination intensity and pollination synchrony on fruit set, development, and harvested yield in cacao.

\section{Trial 1: Assessing the effects of artificial pollination and maternal and paternal genotype cross on harvested yield in three high-yielding cacao clones \\ Study site, clones, and environment. The} study was conducted using a single clonal cacao field (pollination block I) at the Mars Cocoa Research Center (MCRC), in Tarengge Village, South Sulawesi, Indonesia, from Dec. 2013 to July 2014. The experimental field includes 515 trees of 13 T. cacao genotypes (clones), organized in linear rows using a $3.5 \times 3.5-\mathrm{m}$ planting distance and planted using a randomized block design of eight trees per unique clone block. At the time of the experiment, the trees were 3 years old and producing fruit. The field is under partial shade, with Gliricidia sepium [(Jacq.) Kunth ex Walp.] planted at a $7 \times 7-\mathrm{m}$ planting distance. All cacao trees within the field are propagated clonally using softwood scion cuttings from plagiotropic material, terminally grafted on rootstocks from openpollinated M01 seeds. For the three maternal cacao clones described in this article, peak flowering generally occurs between the months of November and March (Supplemental Fig. 1A) and the major harvest period is usually conducted between June and August (Supplemental Fig. 1B), although these events are variable according to yearly rainfall and flowering. After the peak harvest period, a lower number of pods are produced throughout the remainder of the year until a second minor harvest in October through to December (Supplemental Fig. 1B).

The MCRC has an average annual rainfall of $2754 \mathrm{~mm}$, well distributed over 12 months, with higher than average monthly rainfall between April and June (average, $319 \mathrm{~mm}$ ) and lower than average rainfall between August and November (average, $146.5 \mathrm{~mm}$; the "dry" season) (Spaans, 2016, unpublished data). The MCRC has an annual average temperature range between a minimum of $22.7^{\circ} \mathrm{C}$ and a maximum of $31.7^{\circ} \mathrm{C}$, an annual relative humidity between $80 \%$ and $85 \%$, and an average monthly solar radiation of $217 \mathrm{~W} / \mathrm{m}^{2}$. The soils at the MCRC are classified as Typic Dystrudepts (Soil Survey Staff, 1999), very homogeneous, and with little spatial variation (Spaans, 2016, unpublished data) (see Supplemental Table 2 for soil composition details).

Tree nutrition and management. A onesided drip irrigation system (Netafim, Magal, Israel) was fitted to all cacao trees within the experimental field. Each tree had two drippers, each positioned $\approx 0.5 \mathrm{~m}$ on either side of the tree trunk. Additional drip points were positioned every $1 \mathrm{~m}$ along the length of the irrigation line. Dripper capacity was $4 \mathrm{~L} / \mathrm{h}$ and, before Sept. 2014, the system delivered between 2 and $6 \mathrm{~mm}$ water/ha every day, depending on the season and incidence of rainfall. In Sept. 2014 (during trial 1.2), the supply of dissolved mineral fertilizers to experimental trees was implemented via fertigation through the Netafim drip irrigation system. Fertigation was applied to trees every second day in 4 to $6 \mathrm{~mm}$ water/ha, per day during the dry season and in a more concentrated solution of $2 \mathrm{~mm}$ water in months of increased rainfall. Fertigation provided each tree with 15 applications of fertilizer per month of variable nutrient composition and concentration (Supplemental Table 3), developed to complement the cropping cycle of cacao trees in South Sulawesi.

The cacao trees typically had four to five main branches that formed a "cup-shaped" tree architecture. Light sanitary pruning was conducted as required. Heavy structural pruning was conducted once per year after the main harvest period to maintain manageable and uniform tree architecture.

Experimental trial period and tree selection. Before the current study, no experimentation had been conducted on the experimental trees. Trial 1.1 was conducted over a 7-month period from $19 \mathrm{Dec} .2013$ to 21 July 2014. Trial 1.2 was conducted during the following 7-month period from 25 Aug. 2014 to 17 Mar. 2015. The results obtained from trial 1.2 may have been influenced by the application of experimental treatments in trial 1.1 , as well as fertigation implementation and seasonality, and should be interpreted with this in mind.

Trial 1 evaluated three maternal genotypes (M01, PBC123, and MCC02) and two paternal genotypes: PBC123 (trial 1.1) and BB01 (trial 1.2) (Table 1; see Supplemental Table 1 for clonal evaluations). We selected 40 trees of each maternal genotype (Table 1 ) that were 1) the same age, 2) mature and bearing flowers, 3 ) healthy with no symptoms of disease infection, and 4) of uniform tree architecture. Before the trials, any existing immature cacao fruit (cherelles) and larger developing pods were removed from all trees, 
Table 1. Flower counts, flowers pollinated, harvested pods and proportional harvested yield for each of the unique maternal and paternal genotype crosses and their associated pollination intensity treatments.

\begin{tabular}{|c|c|c|c|c|c|c|c|c|}
\hline \multirow[b]{2}{*}{ Trial no. } & \multicolumn{2}{|c|}{ Genotype } & \multicolumn{6}{|c|}{ Other variables } \\
\hline & Maternal & Paternal & PI & No. of trees & Open flowers & Pollinated flowers ${ }^{\mathrm{z}}$ & Harvested pods & Prop. yieldy \\
\hline \multicolumn{9}{|l|}{ Trial 1.1} \\
\hline & M01 & PBC123 & 100 & 16 & 6,054 & 6,054 & 433 & 0.07 \\
\hline & & Open & - & 24 & 27,427 & - & 230 & 0.01 \\
\hline & $\mathrm{PBC} 123$ & PBC123 & 100 & 16 & 6,465 & 6,465 & 88 & 0.01 \\
\hline & & Open & - & 24 & 21,605 & - & 421 & 0.02 \\
\hline & $\mathrm{MCC} 02$ & $\mathrm{PBC} 123$ & 100 & 16 & 8,653 & 8,653 & 463 & 0.05 \\
\hline & & Open & - & 24 & 15,672 & - & 246 & 0.02 \\
\hline \multicolumn{9}{|l|}{ Trial 1.2} \\
\hline & M01 & BB01 & 100 & 16 & 4,244 & 4,244 & 603 & 0.14 \\
\hline & & Open & - & 24 & 4,563 & - & 85 & 0.02 \\
\hline & $\mathrm{PBC} 123$ & BB01 & 100 & 16 & 2,769 & 2,769 & 670 & 0.24 \\
\hline & & Open & - & 24 & 2,859 & - & 109 & 0.04 \\
\hline & $\mathrm{MCC} 02$ & BB01 & 100 & 16 & 6,169 & 6,169 & 707 & 0.11 \\
\hline & & Open & - & 24 & 2,651 & - & 69 & 0.03 \\
\hline \multicolumn{9}{|l|}{ Trial 2} \\
\hline & M01 & BB01 & 100 & 30 & 7,845 & 7,845 & 1,201 & 0.15 \\
\hline & & & 80 & 10 & $2,716^{x}$ & 2,173 & 486 & 0.22 \\
\hline & & & 60 & 10 & $3,527^{x}$ & 2,116 & 389 & 0.18 \\
\hline & & Open & - & 24 & 16,494 & - & 194 & 0.01 \\
\hline
\end{tabular}

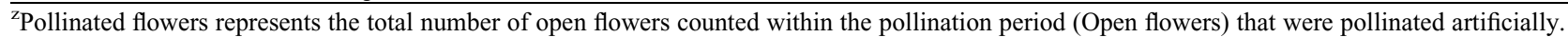

${ }^{\mathrm{y}}$ Prop. yield represents the number of pods harvested within the harvest period, expressed as 1) a proportion of pollinated flowers (for artificial pollination) and 2) a proportion of open flowers (for open pollinations) counted within the pollination period.

${ }^{\mathrm{x}}$ Flower counts are approximations only, calculated using the percentage of open flowers pollinated.

$\mathrm{PI}=$ pollination intensity treatment.

minimizing possible resource competition and compensation effects from nonexperimental fruit.

Flowering intensity. Before flowering intensity (the number of flowers per tree per observation date) evaluations, the total branch area per tree used for experimental trials was standardized for each experimental tree. For this, the lowest $20 \mathrm{~m}$ of branch area was determined and the upper limits of each branch clearly marked with nontoxic red paint (tree branches were not pruned to this length). Branch material existing outside the $20-\mathrm{m}$ experimental branch area or on the trunk was excluded from experimental trial. To evaluate the effects of the experimental treatments on flowering intensity within each trial period, we counted the number of newly opened flowers per tree on 10 observation dates coinciding with the artificial pollination of flowers: between 19 Dec. 2013 and 21 Jan. 2014 for trial 1.1 and between 26 Aug. 2014 and 27 Sept. 2014 for trial 1.2 (Table 1). Flower counts were conducted between 0600 and 1200 HR. Furthermore, natural flowering intensity of open-pollinated trees (see the next section for a description) was monitored continuously between July 2014 and Dec. 2016 (Supplemental Fig. 1).

Artificial pollination. To evaluate the effect of artificial pollination compared to natural pollination on harvested yield, we randomly selected 16 experimental trees per maternal genotype for an "artificial" pollination treatment, whereby $100 \%$ of all open flowers within the experimental branch area were pollinated artificially. Furthermore, 24 trees for each genotype were assigned to an "open" pollination treatment, whereby no flowers received artificial pollination. The open pollination treatment was considered to be the control.
The artificial pollination of flowers was conducted on 33 successive pollination dates between 19 Dec. 2013 and 19 Jan. 2014 for trial 1.1 and between 25 Aug. and 27 Sept. 2014 for trial 1.2. Paternal genotype pollen for the artificial pollinations was obtained by collecting freshly opened flowers of known PBC123 and BB01 trees for trial 1.1 and trial 1.2, respectively, between 0600 and 0700 HR. All collected flowers were stored in a sealed plastic container in a cool location and out of direct sunlight. Artificial pollination was conducted by removing three pollen-filled anthers (attached to stamen) from the collected paternal flowers and brushing them along the stigma of each maternal flower (Falque et al., 1995). Artificial pollination was conducted between 0600 and $1200 \mathrm{HR}$, and each artificially pollinated flower was given a pollination date tag attached to the main branch directly adjacent to the flower pedicel. On average, $\approx 13$ flowers were pollinated per tree per day for trial 1.1 and $\approx 8$ flowers were pollinated per tree per day for trial 1.2 (Table 1) regardless of clone. To reduce the possible effects of pollinators, pollination date and/or time on pollination success, and persons conducting the pollination were circulated randomly throughout the experimental field, and all trees were pollinated at random on each pollination date. For practicality, pollinated flowers were not isolated and artificial pollination was considered supplemental pollination.

A weather station installed at the MCRC on 22 Apr. 2014 showed no significant variation in temperature (average daily mean and average daily maximum) during the pollination period or the entire trial period of trial 1.2 .

Maternal and paternal genotype cross. The potential effects of maternal and paternal genotype cross on yield was nested within the broader artificial pollination treatment. For trial 1.1, the artificial pollination of flowers (see previous section) was conducted between the paternal genotype $\mathrm{PBC} 123$ and the three maternal genotypes (M01, PBC123, and MCC02) (Table 1). PBC123 was selected as the original pollen donor for its reported self-compatibility (Lee et al., 1993) as well as for its dominant presence in large monoclonal, high-yielding cacao plantations within Malaysia and high popularity among smallholder Indonesian farmers. However, as a result of unexpected results in trial 1.1 indicating selfincompatibility of $\mathrm{PBC} 123$, clone BB01 was used as the paternal pollen donor in trial 1.2 (Table 1). Therefore, the genotype labeled PBC123 at the MCRS and used in this study may have been an off type. BB01 was selected as the pollen donor for the second trial as preliminary trials evaluating incompatibility in numerous clones from the MCRS suggested $\mathrm{BB} 01$ as the most cross-compatible clone available.

Harvested yield. All ripe cacao pods were harvested on six dates between 22 May and 21 July 2014 for trial 1.1 and between 30 Jan. and 17 Mar. 2015 for trial 1.2. Upon harvest, count data of all harvested pods were recorded per tree and combined as a total pod count per tree for statistical analysis. Harvested pod counts included only healthy, ripe pods and excluded large and/or mature (unripe) pods that were also removed from the experimental trees as a result of cocoa pod borer or Phytophthora palmivora infection.

Statistical analysis. To evaluate the effects of flowering intensity, artificial pollination, and unique genotype cross on harvested yield, harvested yield data collected from trial 1.1 and trial 1.2 were combined for analysis. For all analyses, we conducted generalized linear mixed models using the 
and lmer (flowering intensity) and glm (harvested yield) functions in the nlme package (Pinheiro et al., 2018) in R (version 3.2.4; R Core Team, 2013). To account for possible variation explained by paternal pollen donor and/or trial period differences, the models each included a fixed effect of trial period. To establish the significance of each fixed effect, we performed likelihood ratio tests for each fixed effect and their interactions using the lrtest function in the lmtest package (Zeileis and Hothorn, 2002) in R (R Core Team, 2013). We were unable to determine whether potential differences in the response variables were the result of the effects of trial period or pollen donor because a different pollen donor was used in each of the two successive trial periods [i.e., PBC123 (pat.) in trial 1.1 and BB01 (pat.) in trial 1.2]. Thus, these results should be interpreted accordingly.

Flowering intensity. We evaluated potential differences in flowering intensity between the maternal clone groups subjected to two differing pollination treatments (open, artificial) across two successive trial periods using a general linear mixed model. We included flowering intensity as the response variable; pollination treatment, maternal genotype, and trial period were used as the fixed effects. The models also included all possible interaction terms between the fixed effects as well as a random effect of tree to account for the repeated sampling of trees across time.

Effects of artificial pollination and genotype cross on harvested yield. As result of possible differences in pollination numbers arising from flowering variability, for the analyses, harvested pod counts relative to the number of flowers pollinated artificially (for artificial pollination) or per available flower (for open pollination), hereafter referred to as "proportional harvested yield," were used (Table 1). To evaluate the effects of artificial pollination, unique maternal $\times$ paternal genotype cross, and trial period on harvested yield, the generalized linear mixed models included proportional harvested yield as the response variable and pollination treatment, maternal genotype, and trial period as fixed effects. The models also included all possible interaction terms between the fixed effects and assumed a binomial distribution with a logit-link function. Estimates and confidence intervals were relative to the harvested yield obtained by the M01 clone under artificial pollination in trial 1.1.

\section{Trial 2: Assessing the effects of} pollination intensity and pollination synchrony on fruit set, cherelle wilt, and harvested yield in M01-a high-yielding cacao clone

Study site, clones, and environment. The study was conducted using a single clonal cacao field (pollination block II) at the MCRC from Feb. 2015 to Aug. 2015. Pollination block II is directly adjacent to pollination block I, separated only by a small road (width, $\approx 4 \mathrm{~m}$ ). Pollination block II was planted using a randomized planting arrangement of 10 cacao clones, predominantly clone M01. The experimental trial was conducted using clone M01 as the maternal genotype. This clone was selected because of the adequate number of replicate trees existing at the MCRC, as well as for its wide cultivation throughout Indonesia and known production of a high number of large pods with large beans under open pollination conditions (Supplemental Table 1). The propagation techniques used, environmental characteristics of the region, tree phenology, tree nutrition, and management of pollination block II are as described for pollination block I.

Experimental trial period and tree selection. Trial 2 was conducted over a 7 month period from $3 \mathrm{Feb}$. to 22 Aug. 2015. Before the research described, no manipulations or experimentation had been conducted on the experimental trees. We selected 50 experimental trees of the M01 clone (per tree selection described earlier) that were used for artificial pollination. In addition, the 24 M01 trees that were assigned previously to the open pollination treatment in trial 1 (described earlier) were used as the controls.

Flowering intensity and artificial manipulation of pollination intensity. Two weeks before beginning trial 2 , the experimental trees were, twice weekly, stripped of their existing open flowers, immature cacao fruit (cherelles), and larger developing pods to minimize possible resource competition and compensation effects from nonexperimental fruit [as in Groeneveld et al. (2010)] Flowering intensity was determined in the same manner as described earlier, regardless of pollination treatment, and was conducted between 3 Feb. and 6 Mar. 2015 (Table 1). To examine the effects of pollination intensity on harvested yield, we conducted artificial pollination on 50 experimental cacao trees within a 31-day pollination period between 3 Feb. 2015 and 5 Mar. 2015. Each experimental tree was selected randomly for one of three pollination intensity treatments including 1) $60 \%$ of the open flowers pollinated artificially, 2) $80 \%$ of the open flowers pollinated artificially, and 3) $100 \%$ of the open flowers pollinated artificially (Table 1). Thus, pollination intensity represents the percentage of all open flowers that were pollinated artificially per tree on each pollination date. Clone BB01 was used as the paternal pollen donor for artificial pollination (Table 1). For the open pollination control trees $(0 \%)$, no flowers were pollinated artificially.

After flower counting on each pollination date, the number of flowers to be pollinated artificially was determined at the branch level as a percentage of all open flowers on a given branch, according to the pollination intensity treatment assigned. This method was applied to all main branches within each tree. Flowers on each branch were then selected at random and pollinated artificially as de- scribed earlier. Because of rainfall events on 7 days within the pollination period, pollination was conducted for $24 \mathrm{~d}$. No significant variation in temperature (average daily mean and average daily maximum) was observed during the pollination period or trial period of trial 2.

Pollination synchrony. We describe pollination synchrony as the temporal distribution of artificial pollination within a 5-week pollination period. All flowers that were pollinated artificially were given unique tags, each coded by pollination date and pollination week (i.e., weeks 1-5). These unique date tags were used to evaluate the success of pollinated flowers and developing cherelles (see next section). The importance of pollination synchrony was determined using the fruit-setting success, as well as the relative survival of cherelles and harvested pods for each of the five pollination weeks.

Cherelle development. The development of cherelles set by artificial pollination was monitored weekly until either cherelle wilt (abortion) or the harvest of a matured pod, with the first monitoring event on 7 Feb. 2015, 4 days after the first pollination date. Cherelle development was monitored by counting the number of surviving cherelles per tree present on each monitoring occasion, grouped by pollination week for practicality. Because cherelle set by natural pollination may incur additional resource competition with and/or between developing cherelles set by artificial pollination, we also tagged and monitored any cherelles set by natural pollination.

Harvested yield. The harvesting of cacao pods in trial 2 was conducted fortnightly during an 8-week harvest period between 27 June 2015 to 22 Aug. 2015 upon observation of ripe pods. Pod harvesting was conducted as described earlier.

Statistical analysis. To evaluate the effects of pollination intensity $(60 \%, 80 \%$, or $100 \%$ ) and pollination synchrony (pollination weeks 1-5) on fruit development, cherelle survival was analyzed using three distinct time periods including 1) fruit set [0-25 d after pollination (DAP)], 2) cherelle wilt (26-160 DAP), and 3) harvest (161-180 DAP). Cherelle survival was standardized to begin from the date that each flower was pollinated artificially ( 0 DAP) and was expressed as a proportion relative to the total number of flowers pollinated artificially per tree per pollination date and within each of the five pollination weeks.

Fruit set and harvested yield. To evaluate the effects of pollination intensity and synchrony on proportional fruit set and proportional harvested yield, generalized linear mixed models using the glmer function in the lme4 package (Bates et al., 2015) in $\mathrm{R}$ ( $\mathrm{R}$ Core Team, 2013) were conducted using either 1) the proportion of surviving cherelles within the fruit set period (0-25 DAP) or 2) the proportional harvested yield as the response variables. The fixed effects in the 
Table 2. General (flowering intensity) and generalized (harvested yield) linear mixed-model results for flowering intensity and harvested yield in trial 1.

\begin{tabular}{|c|c|c|c|c|c|c|}
\hline \multirow[b]{2}{*}{ Fixed effect ${ }^{\mathrm{z}}$} & \multicolumn{3}{|c|}{ Flowering intensity } & \multicolumn{3}{|c|}{ Proportional harvested yield } \\
\hline & $\chi^{2}$ & df & $P$ value $^{y}$ & $\chi^{2}$ & df & $P$ value ${ }^{y}$ \\
\hline Pollination treatment & 77.90 & 9 & $<0.0001$ & 102.41 & 1 & $<0.0001$ \\
\hline Maternal genotype & 19.10 & 8 & $<0.0001$ & 41.58 & 2 & $<0.0001$ \\
\hline Trial & 812.95 & 9 & $<0.0001$ & 18.72 & 1 & $<0.0001$ \\
\hline Pollination treatment $\times$ Maternal genotype & 23.98 & 12 & $<0.0001$ & 54.07 & 2 & $<0.0001$ \\
\hline Pollination treatment $\times$ Trial & 1493.40 & 12 & $<0.0001$ & 0.012 & 1 & 0.9115 \\
\hline Maternal genotype $\times$ Trial & 49.86 & 12 & $<0.0001$ & 67.28 & 2 & $<0.0001$ \\
\hline Pollination treatment $\times$ Maternal genotype $\times$ Trial & 116.42 & 14 & $<0.0001$ & 22.34 & 2 & $<0.0001$ \\
\hline
\end{tabular}

${ }^{\mathrm{z}}$ Fixed effects included pollination treatment (open, artificial), maternal genotype (M01, PBC123, MCC02), and trial period (trial 1.1 and trial 1.2). The models included both two-way and three-way interaction terms between fixed effects.

${ }^{\mathrm{y}}$ All $P$ values were calculated using test statistics derived from the mean and variance.

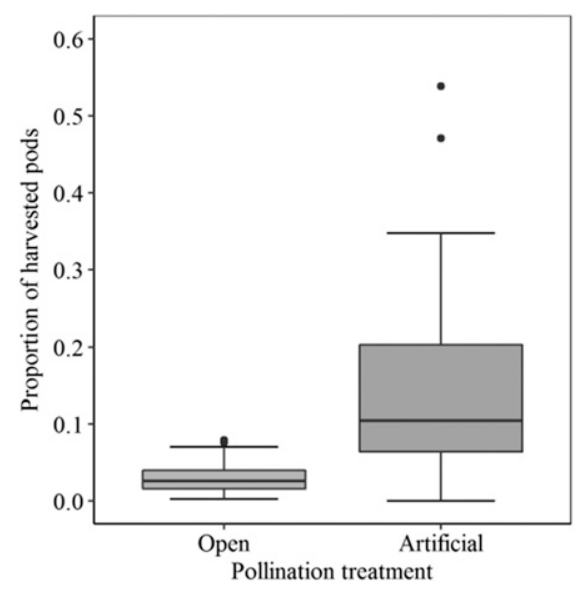

Fig. 1. Proportional harvested yield for each of the two pollination treatments (open, artificial). For the open pollination treatment, harvested yield represents the proportion of available flowers counted that were harvested as pods. For the artificial pollination treatment, harvested yield represents the proportion of pollinated artificially flowers that were harvested as pods. Here, harvested yield data for each unique genotype cross was grouped by pollination treatment.

models included 1) pollination intensity treatment, 2) pollination week, and 3) a pollination intensity-by-pollination week interaction term (used in the analysis of fruit set only as a result of nonconvergence for the interaction term at harvest). Because individual trees were measured repeatedly across time, a random effect of tree was included in the models. The models each assumed a binomial distribution with a logit-link function. To establish the significance of each fixed effect, we performed sequential likelihood ratio tests for each fixed effect and their interactions using the lrtest function in the lmtest package (Zeileis and Hothorn, 2002) in R (R Core Team, 2013).

Cherelle wilt. To evaluate the effects of pollination intensity and synchrony on cherelle survival during the cherelle wilt period (26-160 DAP), a quadratic linear regression was fit to the data using the $1 \mathrm{~m}$ function in $\mathrm{R}$ ( $\mathrm{R}$ Core Team, 2013). The proportion of surviving cherelles was used as the response variable and the main effects included a categorical covariate effect for pollination treatment, a categorical effect for pollination week, as well as effects describing the linear number of days after pollination and the square of days after pollination. The goodness of fit was described using the model's $R^{2}$ value.

\section{Results}

\section{Trial 1 results}

Flowering intensity. Flowering intensity differed between trees subject to each of the two pollination treatments $\left(\chi^{2}=\right.$ 77.90, $\mathrm{df}=9, P<0.0001$; Table 2) and pollination effects depended on the maternal genotype and trial period, as shown by the significant interaction terms between pollination treatment and maternal genotype $\left(\chi^{2}=23.98\right.$, df $=12, P<0.0001$; Table 2$)$ and trial period $\left(\chi^{2}=812.95, \mathrm{df}=\right.$ 9, $P<0.0001$; Table 2). Across both trial periods, mean flowering intensity per tree per day was greatest under open pollination conditions (52, $\mathrm{n}=24$; Table 1$)$ compared to artificial pollination $(22, \mathrm{n}=16$; Table 1$)$, suggesting a negative effect of artificial pollination on flowering intensity. We also observed a significant three-way interaction between pollination treatment, maternal genotype, and trial period $\left(\chi^{2}=116.42\right.$, $\mathrm{df}=14, P<0.0001)$. Across both trials, trees under artificial pollination conditions and maternal genotype $\mathrm{MCC} 02$ produced, on average, more flowers per tree per day $(29, \mathrm{n}=16$; Table 1). However, under open pollination conditions and across both trials, it was maternal genotype M01 that produced the greatest mean flowering intensity $(67, \mathrm{n}=40$; Table 1$)$. Flowering intensity, regardless of pollination treatment and maternal genotype was greater in trial 1.2 compared to trial 1.1 (Table 1 ). This may have been a result of seasonality or possible indirect effects on flowering caused by the pollen donor.

Effects of artificial pollination and genotype cross on harvested yield. Across all clones, a total of 34,354 flowers were pollinated artificially during the two successive trials periods, which led to 2964 artificially pollinated ripe pods being harvested (Table 1). A highly significant effect of the pollination treatment was found on harvested yield $\left(\chi^{2}=102.41\right.$, df $=1, P<0.0001$; Fig. 1 , Table 2), in which artificial pollination showed a significant positive effect on yield
(Fig. 1, Table 2). For trees assigned to the open pollination treatment, 1160 ripe pods were harvested during the two successive trials periods (Table 1).

We found highly significant effects of trial period $\left(\chi^{2}=18.72, \mathrm{df}=1, P<0.0001\right.$; Fig. 2, Table 2$)$ and maternal genotype $\left(\chi^{2}=\right.$ $41.58, \mathrm{df}=2, P<0.0001$; Fig. 2 , Table 2 ) on harvested yield. This may be largely driven by differences in compatibility between unique maternal and paternal genotype crosses (Fig. 2), as shown by the significant maternal genotype $\times$ trial period interaction term $\left(\chi^{2}=67.28, \mathrm{df}=2, P<0.0001\right.$; Fig. 2 , Table 2 ), as a different pollen donor was used in each trial period. However, the significant pollination treatment $\times$ maternal genotype $\times$ trial period three-way interaction term $\left(\chi^{2}=\right.$ 22.34, df $=2, P<0.0001$; Fig. 2, Table 2) may indicate that the effects of artificial pollination, regardless of pollen genotype, varied across the two trial periods for each of the maternal clone groups and, thus, additional factors unrelated to genotype compatibility, such as environmental factors, may be influencing harvested yield.

The greatest harvested yield $(24 \%$ of pollinated flowers survived to harvest) was obtained from the PBC123 (mat.) $\times \mathrm{BB} 01$ (pat.) genotype cross (Fig. 2, Table 1). Furthermore, harvested yield in each maternal genotype was always greater when BB01 was used as the pollen donor (Fig. 2, Table 1).

\section{Trial 2 results}

Pollination intensity and synchrony. A total of 12,134 flowers were pollinated artificially across the 50 experimental trees assigned to the artificial pollination treatment during trial 2 , regardless of pollination intensity (Table 1). This led to the harvest of 2076 ripe pods during trial 2 (Table 1). For artificially pollinated trees, cherelles arising from natural pollination were observed only in the $60 \%(\mathrm{n}=798$ cherelles $)$ and $80 \%(\mathrm{n}=$ 486 cherelles) artificial pollination treatments. However, no naturally pollinated cherelles observed on artificially pollinated trees survived to harvest (cherelles wilted). Therefore, cherelle survival and harvested yield data were expressed relative to artificial pollination only. For trees assigned to the open pollination treatment, 194 ripe pods were harvested during the harvest period of trial 2 (Table 1). 


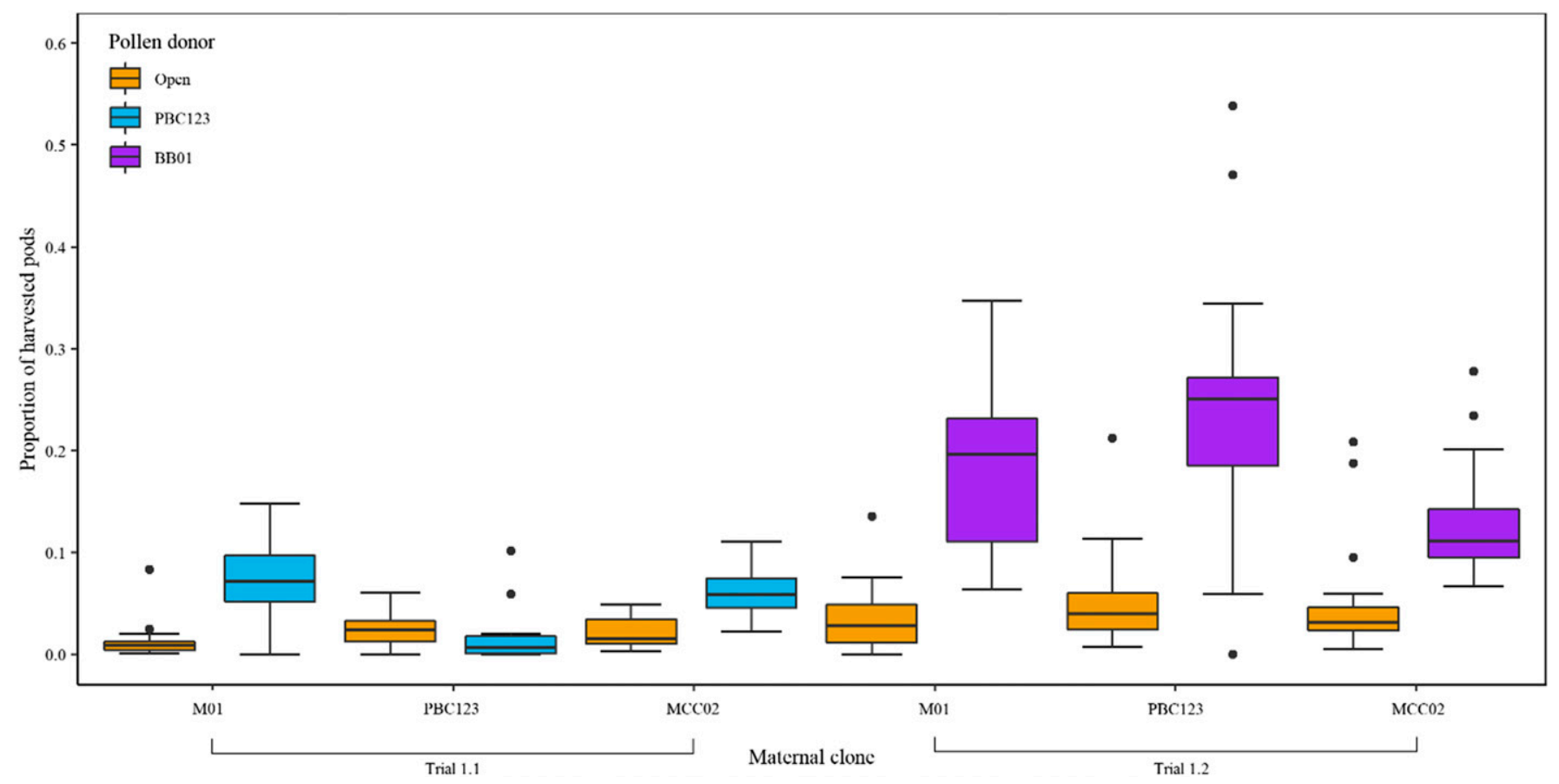

Fig. 2. Proportional harvested yield for each of the unique maternal and paternal genotype crosses. Harvested yield represents the number of harvested pods per maternal clone (M01, PBC123, MCC02) as a proportion of 1) the number of open flowers produced per tree during the pollination period for trees assigned to the open pollination treatment (open, orange) or 2) the number of flowers pollinated artificially [trees pollinated artificially by paternal pollen donors PBC123 (blue) or BB01 (purple)] from each of two successive trial periods (trial 1.1 and trial 1.2).

Fruit set $(0-25$ DAP). A significant effect of pollination intensity treatment $\left(\chi^{2}=13.00\right.$, $\mathrm{df}=2, P=0.001$; Fig. $3 \mathrm{~A}, \mathrm{D}, \mathrm{G})$ and pollination week $\left(\chi^{2}=267.93\right.$, df $=4, P<$ 0.0001 ; Fig. 3A, D, G) was found on cherelle survival during the fruit set period, as well as a highly significant interaction effect between pollination intensity treatment and pollination week $\left(\chi^{2}=718.30, \mathrm{df}=8, P<\right.$ 0.0001; Fig. 3A, B, D, E, G, H).

Seven of the eight possible pairwise comparisons between the $100 \%$ pollination intensity in pollination week 1 and the $60 \%$ and $80 \%$ pollination intensity treatments and the remaining four pollination weeks showed a statistically significant effect on the proportion of surviving cherelles (Fig. 3G, Table 3).

Cherelle wilt (26-160 DAP). We observed significant linear and squared components of the quadratic relationship between the proportion of surviving cherelles within the cherelle wilt period and the number of days after pollination $(\mathrm{F}=$ 3229.80, df $=1, P<0.001$; Fig. 3B, E, H) and the square of the number of days after pollination $(\mathrm{F}=52.04, \mathrm{df}=1, P<0.001)$ for each of the three pollination intensity treatments. We also found a significant effect of pollination intensity treatment $(\mathrm{F}=223.02$, df $=2, P<0.0001$; Fig. 3B, E, H) and pollination week $(\mathrm{F}=344.50, \mathrm{df}=4, P<$ 0.0001 ; Fig. $3 \mathrm{~B}, \mathrm{E}, \mathrm{H})$ on cherelle survival within the cherelle wilt period. Across all pollination intensity treatments, cherelle survivorship was greatest for cherelles originating in pollination week 1 , with decreasing survivorship in each successive week (Fig. 3B, E, H). Only cherelle survival for cherelles originating in pollination week 2 was found not to be significantly different from pollination week 1 , whereas cherelle survival for cherelles originating in weeks 3,4 , and 5 was significantly less than that of pollination week 1 . In the model, increases in both the pollination week and the number of days after pollination caused a decreasing proportion of surviving fruit. The model displayed a high adjusted $R^{2}$ value of 0.80 .

Harvested yield. A significant effect of pollination intensity treatment $\left(\chi^{2}=22.51\right.$, df $=2, P<0.0001$; Fig. $3 \mathrm{C}, \mathrm{F}, \mathrm{I})$ and pollination week $\left(\chi^{2}=1091.50, \mathrm{df}=4, P<\right.$ 0.0001 ; Fig. $3 \mathrm{C}, \mathrm{F}, \mathrm{I})$ was found on harvested pod counts, with the model fitting both effects displaying a lower Akaike information criterion value. For this model, we observed that although the pollination intensity treatment effect displayed equal variance, there were unequal variances across pollination weeks, with the residuals following the trend of the harvest data (Fig. 3C, F, I). Contrasts between each of the fixed effects were estimated relative to the $100 \%$ pollination treatment and pollination week 1 (Table 4 ). The $80 \%$ pollination intensity treatment displayed the greatest proportion of harvested pods relative to the number of artificial pollination treatments (Table 1). Overall, the greatest harvested yield was obtained from pods originating in pollination week 1 (Fig. 3C, $\mathrm{F}, \mathrm{I})$, regardless of pollination intensity treatment. Moreover, we found a clear decreasing trend in the proportion of surviv- ing cherelles and the number of harvested pods, with increasing pollination week (Fig. 3).

\section{Discussion}

Artificial pollination and genotype cross effects. In both trials, artificial pollination significantly increased the harvested yield. Open pollination resulted in low flower-tofruit conversion rates, supporting previous findings documenting pollination as a major extrinsic factor limiting cacao production (Falque et al., 1995, 1996; Groeneveld et al., 2010; Young, 1982, Young and Severson, 1994). Interestingly, the observed yield benefits of artificial pollination for the maternal genotypes varied by paternal genotype in trial 1. Such variation in fertilization success may be the result of physiological differences between the pollen donors (Campbell and Halama, 1993), perhaps regulated by other genes not directly involved with crosscompatibility. We also observed large yield variation between different maternal genotypes when pollinated using the same pollen donor. For example, the benefit of artificial pollination for the cross PBC123 (mat.) $\times$ BB01 (pat.) was double the benefit observed for $\mathrm{MCC} 02$ (mat.) $\times \mathrm{BB} 01$ (pat.). These observed maternal effects may be the result of genotype-specific variation in physiological parameters that contribute to pod development, such as photosynthetic rate, which may lead to different pod carrying capacities and harvested yields for the maternal genotypes tested (Daymond et al., 2011). The variation between maternal genotypes in their 
A) $60 \%$ pollination: fruit set (0-25 DAP)

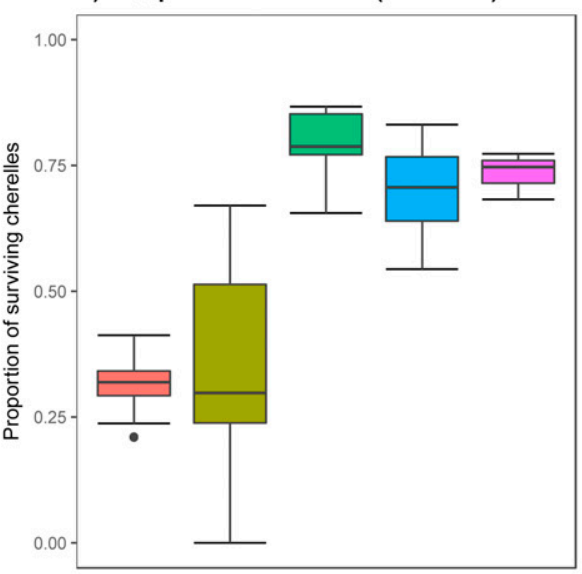

D) $80 \%$ pollination: fruit set (0-25 DAP)

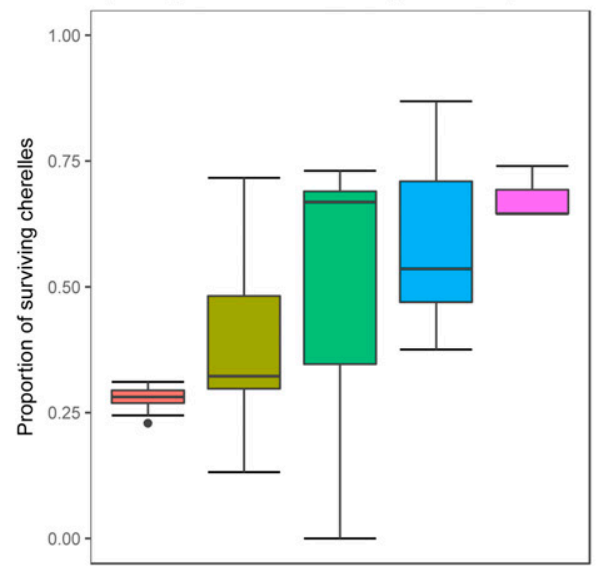

G) $100 \%$ pollination: fruit set (0-25 DAP)

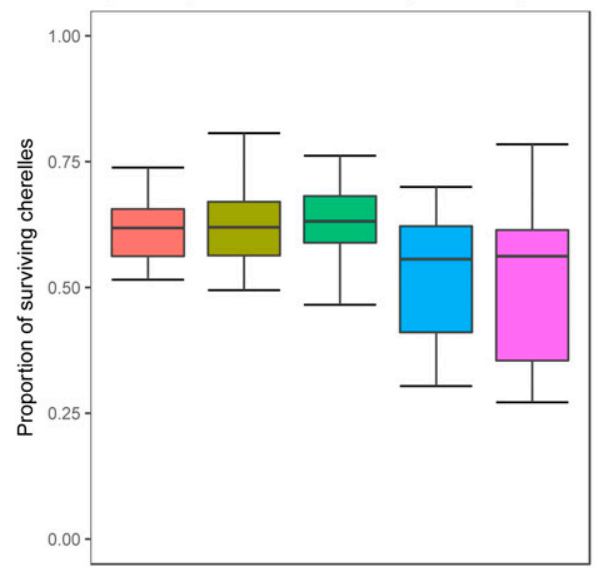

B) $60 \%$ pollination: cherelle wilt (30-160 DAP)

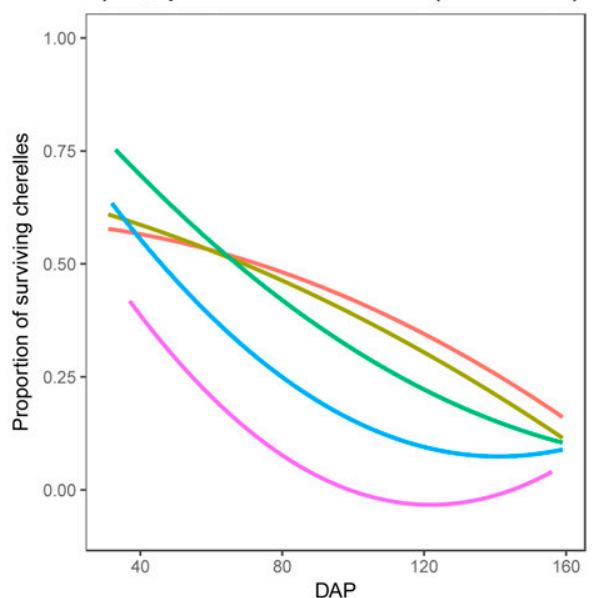

E) $80 \%$ pollination: cherelle wilt (30-160 DAP

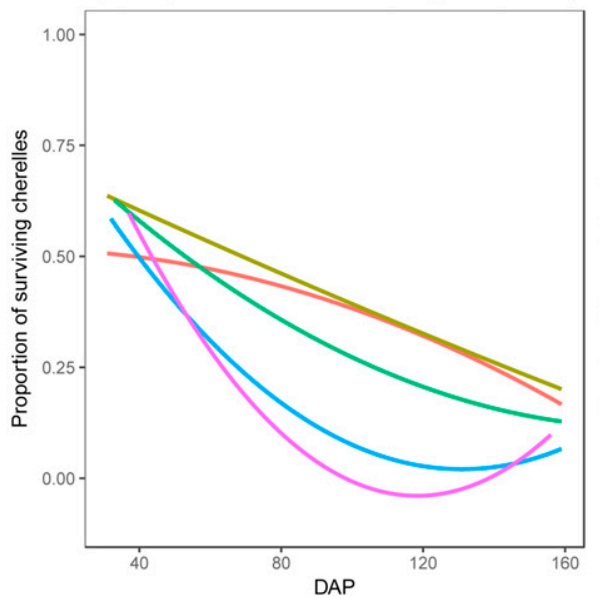

H) $100 \%$ pollination: cherelle wilt (30-160 DAP)

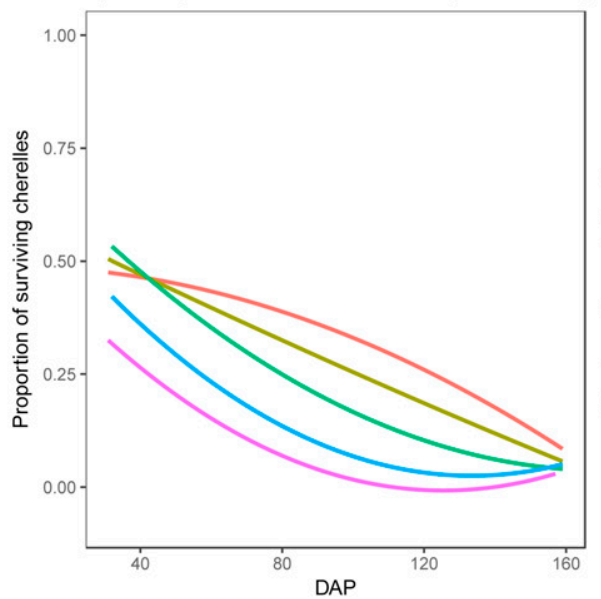

C) $60 \%$ pollination: harvest

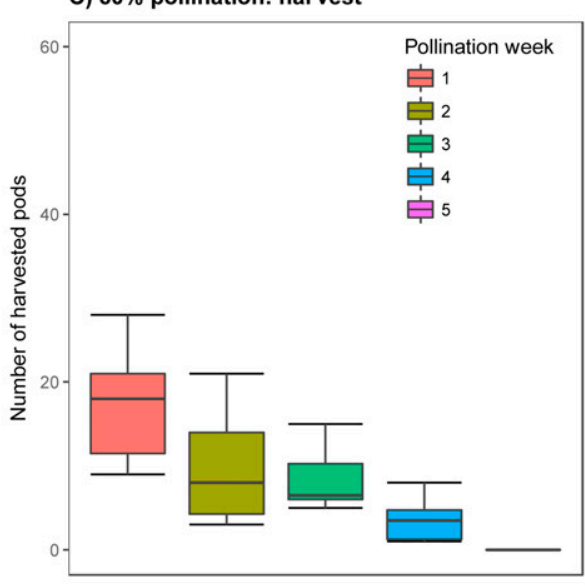

F) $80 \%$ pollination: harvest

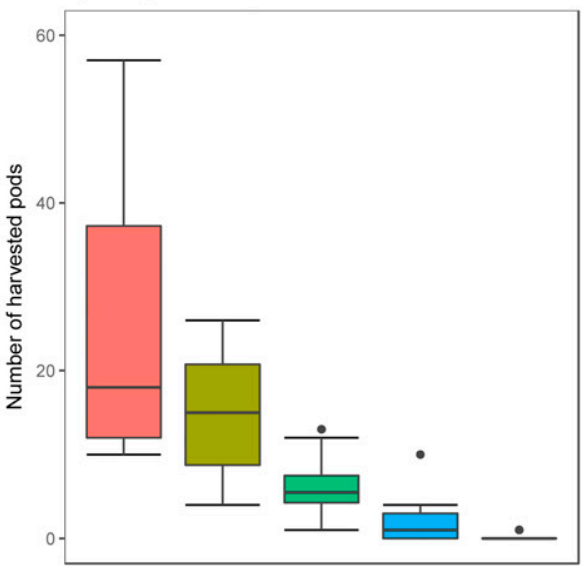

I) $100 \%$ pollination: harvest

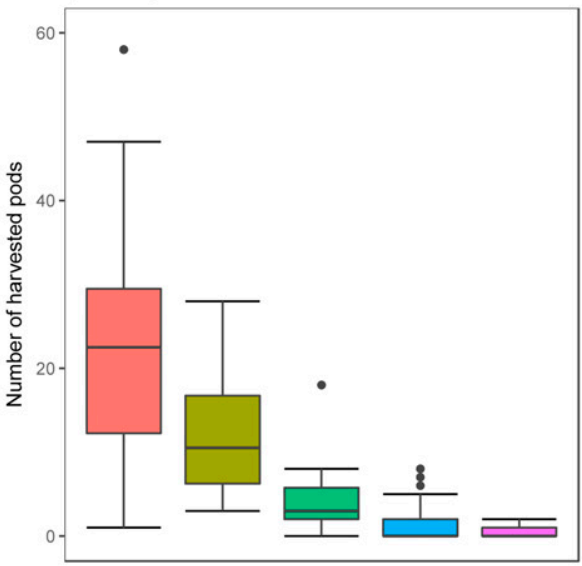

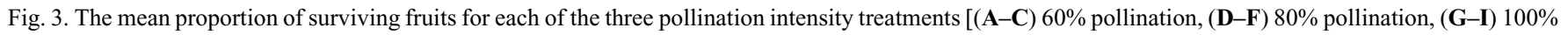
pollination], originating in each of the five pollination weeks (pollination weeks $1-5$ represented by red, gold, green, blue, and purple, respectively) during three distinct fruit developmental stages including fruit set [0-25 days after pollination (DAP) (A, D, G)], cherelle wilt [26-160 DAP (B, E, H)], and harvest $(\mathbf{C}, \mathbf{F}, \mathbf{I})$. Boxplots are used for the representation of fruit set [0-25 DAP (A, D, G); Table 2] and harvest (C, F, I; Table 3) data, whereas a quadratic linear regression was fit to represent cherelle wilt [26-160 DAP (B, E, H)] data (see trial 2 results; cherelle wilt, 26-160 DAP).

responses to artificial pollination highlights that our results cannot be generalized for all cacao clones, and the benefits of artificial pollination remain genotype-cross specific.

Pollination synchrony. The most novel finding of our study is that we found a significant effect of pollination synchrony on cherelle survivorship during periods of fruit set, cherelle wilt, and harvest. Cherelles originating within earlier pollination weeks (older cherelles) had a progressively greater survivorship than those originating in later pollination weeks (younger cherelles). The greatest proportional harvested yield obtained arose from clustered artificial pollination treatments early during the pollination period, suggesting that synchronized pollination events may maximize cacao yield. Our results support the earlier findings of Hutcheon (1977), who found increased cherelle wilt toward the end of the cropping season and suggested that between-pod competition for a declining reserve of assimilate resources was the causal mechanism. Similar findings 
Table 3. Generalized linear mixed-model results for proportional fruit set in trial 2.

\begin{tabular}{|c|c|c|c|c|}
\hline Effect $^{2}$ & Parameter estimate & $\mathrm{SE}$ & $\mathrm{z}$ Value & $P$ value \\
\hline Pollination intensity, $80 \%$ & -0.9502 & 0.12780 & -7.435 & $<0.0001$ \\
\hline Pollination week 2 & 0.05117 & 0.03492 & 1.465 & 0.1428 \\
\hline Pollination week 4 & -0.18092 & 0.04267 & -4.240 & $<0.0001$ \\
\hline Pollination week 5 & -0.35617 & 0.05122 & -6.953 & $<0.0001$ \\
\hline Pollination intensity $(60 \%) \times$ Pollination week 2 & 0.25144 & 0.07253 & 3.467 & $<0.0001$ \\
\hline Pollination intensity $(60 \%) \times$ Pollination week 5 & 1.10363 & 0.17099 & 6.454 & $<0.0001$ \\
\hline Pollination intensity $(80 \%) \times$ Pollination week 2 & 0.10092 & 0.07063 & 1.429 & 0.1531 \\
\hline Pollination intensity $(80 \%) \times$ Pollination week 3 & 1.63755 & 0.09487 & 17.262 & $<0.0001$ \\
\hline Pollination intensity $(80 \%) \times$ Pollination week 4 & 1.58153 & 0.09415 & 16.798 & $<0.0001$ \\
\hline Pollination intensity $(80 \%) \times$ Pollination week 5 & 1.82103 & 0.14097 & 12.918 & $<0.0001$ \\
\hline
\end{tabular}

${ }^{\mathrm{z}}$ Fixed effects included pollination intensity treatments and pollination week. The intercept was the $100 \%$ pollination intensity treatment during pollination week 1 .

${ }^{\mathrm{y}}$ All $P$ values were calculated using test statistics derived from the mean and variance.

Table 4. Generalized linear mixed-model results for proportional harvested yield in trial 2.

\begin{tabular}{|c|c|c|c|c|}
\hline$\overline{\text { Effect }^{2}}$ & Parameter estimate & SE & z Value & $P$ value $^{\mathrm{y}}$ \\
\hline Intercept & -1.27616 & 0.08896 & -14.346 & $<0.0001$ \\
\hline Pollination intensity, $80 \%$ & 0.52703 & 0.16875 & 3.123 & 0.00179 \\
\hline Pollination week 2 & -0.24867 & 0.05183 & -4.798 & $<0.0001$ \\
\hline Pollination week 4 & -2.15847 & 0.10347 & -20.861 & $<0.0001$ \\
\hline Pollination week 5 & -3.27340 & 0.28097 & -11.650 & $<0.0001$ \\
\hline
\end{tabular}

${ }^{\mathrm{z}}$ Fixed effects included pollination intensity treatments and pollination week. The intercept was the $100 \%$ pollination intensity treatment during pollination week 1 .

${ }^{\mathrm{y}}$ All $P$ values were calculated using test statistics derived from the mean and variance.

have been reported in maize (Zea mays L.), where synchronized artificial pollination increased kernel set and yield (Carcova et al., 2000; Carcova and Otegui, 2001; Freier et al., 1984; Harris et al., 1976; Sarquis et al., 1998; Struik and Makonnen, 1992). However, access to and competition for a limited supply of local assimilates is also a major driver of postfertilization kernel abortion (Shen et al., 2018).

In cacao, competition for assimilate resources can exist both between structural types (such as between flowers and fruit) or within structural types (such as between developing pods). Flowering intensity (Valle et al., 1990), cherelle survival (Wood and Lass, 1985), and the number and size of seeds per pod (Falque et al., 1995) are all reported to decrease with an increasing number of developing pods, resulting from the competition for resources. Thus, the observed increased survivorship of cherelles originating from clustered pollination events within earlier pollination weeks may be the result of high resource availability at the time of pollination paired with low competitive hierarchy among cherelles. This increased survivorship of older cherelles generally suggests that older fruit (larger resource sinks) may exert dominance in the sequestration of limited assimilates. This is also supported by the observed abortion of all naturally pollinated cherelles in our trial 2 . However, it is also possible that the increased survivorship of older cherelles is the result of an alteration in the maternal plants' pattern of assimilate partitioning, mediated by synchro- nized pollination events in which the maternal tree invests resources preferentially to structures that are more likely to mature, thus selectively aborting weaker structures (De Jong and Klinkhamer 2005; Uma Shaanker et al., 1988; Stephenson 1981). Alterations in the pattern of assimilate partitioning arising from synchronous pollination have been reported previously in maize (Lafitte and Edmeades, 1995), and further investigation of this potential physiological phenomenon in cacao is recommended.

Pollination intensity. Pollination intensity effects were dependent on the pollination week. The interaction between pollination intensity and pollination week observed for trees assigned to the $60 \%$ and $80 \%$ pollination intensity treatments may be a result of fewer pollinated flowers per tree during the earlier pollination weeks (compared to the $100 \%$ treatment). Here, weak sink effects may be underlying the lower fruit set rates during times of presumably unlimited resources and may be further exacerbated by low flowering intensity during the earlier pollination weeks. When flowering intensity is low, increased pollination intensity appears advantageous to fruit set, possibly by establishing a stronger resource sink (e.g., an increased number of developing cherelles) driving the internal plant physiological processes (i.e., assimilate production and/or remobilization, hormone production) that support the fertilization success of subsequently pollinated flowers (Arathi, 2011).

Despite the $100 \%$ pollination intensity treatment involving the greatest proportional fruit set (0-25 DAP), the $80 \%$ pollination intensity treatment produced the greatest proportional harvested yield. These results indicate that, although the benefits of increased pollination intensity on yield may erode as cherelle wilt increases, this offset may be only partial. The total number of pods harvested per tree in trial 2 remained greatest in the $100 \%$ pollination intensity treatment despite increasing rates of cherelle wilt, still reflecting the benefits of enhanced artificial pollination. Future research efforts should evaluate the effects of potential interactions between the reproductive sink size, resource availability, the proximity of developing cherelles to assimilate sources, and resource competition within/between plant parts on fruit development in cacao.

In situations in which pollination rates are of concern and when labor costs allow, artificial pollination management strategies have been implemented for cacao (Francis K. Padi, C.R.I.G., 2018, personal communication) as well as other perennial crops (Pinillos and Cuevas, 2008). A hand-pollination program launched in 2017 by the Cocoa Health and Extension Division of the Ghana Cocoa Board observed greater yields than the previous year (Francis K. Padi, C.R.I.G., 2018, personal communication). However, yields of nonpollinated plots during this time were not monitored simultaneously, making actual yield increases difficult to estimate (Francis K. Padi, C.R.I.G., 2018, personal communication). The group's future efforts to compare artificially and naturally pollinated cacao plots have the potential to quantify the yield 
benefits of adopting artificial pollination strategies in low-input, smallholder cacao systems using seed-grown hybrid planting materials (Francis K. Padi, C.R.I.G., 2018, personal communication). These yield benefits may be further enhanced if paired with practices that aim to increase pollination synchrony and also consider cacao tree phenology, physiology, and compatibility. For example, by intensively clustering artificial pollination events within a short time period $(\approx 7-14 \mathrm{~d})$ when flowering intensity is high and competition between developing fruit is low, maximized crop productivity for minimal manual labor inputs may be achieved. However, understanding clone compatibility is vital for the evaluation of such efforts. The temporal clustering of artificial pollinations may lead to synchronous pod ripening, condensed harvest events, subsequent increases in harvesting efficiency, and potential quality improvements resulting from the more homogeneous physiological status of the beans to be fermented. Researching these effects will build upon the research presented here. In situations in which conducting artificial pollination is impractical or unachievable, adopting farm management strategies to enhance and support natural pollinator populations (e.g., the provision or organic substrates for pollinator oviposition and larval development) matched with strategies to increase flowering intensity may also lead to increases in crop productivity and harvesting efficiency.

In conclusion, genetically and agronomically driven strategies in cacao cultivation systems that aim to increase flowering, pollination rates, and pollination synchrony may increase productivity in cacao. Whether the effects of such strategies are reflected in final crop yield likely depends on a wide range of site-specific environmental factors (e.g., nutrient availability, pest pressure, local management, climate) as well as the contextdependent fruit-bearing capacity of the cultivars in use (Bos et al., 2007). Thus, artificial pollination management strategies to increase cacao yields should be evaluated further using genetically diverse genotypes that are self- or cross-compatible, and conducted simultaneously with approaches aimed toward improving postpollination pod retention, overall plant health, and resilience to environmental perturbations. This is important for ensuring the sustainability of the cacao industry and farmer livelihoods, particularly given the increased frequency and severity of climate change-related environmental perturbations (Grassini et al., 2013; Ray et al., 2015). In intensified cacao cultivation systems involving continuous artificial pollination to produce unnaturally high fruit loads, cacao trees may be susceptible to resource reserve depletion, particularly when resources are limiting (Hutcheon, 1977). Assimilate resources may become an increasingly limiting factor of yield, apparent only after numerous years (Muller et al., 1988). For this reason, future research efforts to address the effects of intensive yield- increasing strategies should also be evaluated across multiple years to determine the long-term sustainability of enhancing tree productivity.

\section{Literature Cited}

Aneani, F. and K. Ofori-Frimpong. 2013. An analysis of yield gaps and some factors of cocoa (Theobroma cacao) yields in Ghana. Sustain. Agr. Res. 2(4):117-127.

Arathi, H.S. 2011. Selective embryo abortion in a perennial tree-legume: A case for maternal advantage of reduced seed number per fruit. J. Plant Res. 124(6):675-681.

Ayre, D.J. and R.J. Whelan. 1989. Factors controlling fruit-set in hermaphroditic plants: Studies with the Australian Proteaceae. Trends Ecol. Evol. 4(9):267-272.

Bates, D., M. Maechler, B. Bolker, and S. Walker. 2015. Fitting linear mixed-effects models using lme4. J. Stat. Softw. 67(1):1-48.

Bisseleua, D.H.B., A.D. Missoup, and S. Vidal. 2009. Biodiversity conservation, ecosystem functioning, and economic incentives under cocoa agroforestry intensification. Conserv. Biol. 23(5):1176-1184.

Blommer, P. 2011. A collaborative approach to cocoa sustainability. Manuf. Confect. 91(5): 19-26.

Bos, M.M., I. Steffan-Dewenter, and T. Tscharntke. 2007. Shade tree management affects fruit abortion, insect pests and pathogens of cacao. Agr. Ecosyst. Environ. 120(2-4):201205.

Brown, A.O. and J.N. McNeil. 2006. Fruit production in cranberry (Ericaceae: Vaccinium macrocarpon): A bet-hedging strategy to optimize reproductive effort. Amer. J. Bot. 93(6): 910-916.

Campbell, D.R. and K.J. Halama. 1993. Resource and pollen limitations to lifetime seed production in a natural plant population. Ecology 74(4):1043-1051.

Carcova, J. and M.E. Otegui. 2001. Ear temperature and pollination timing effects maize kernel set. Crop Sci. 41(6):1809-1815.

Carcova, J., M. Uribelarrea, L. Borras, M.E. Otegui, and M.E. Westgate. 2000. Synchronous pollination within and between ears improves kernel set in maize. Crop Sci. 40(4):10561061.

Carr, M.K.V. and G. Lockwood. 2011. The water relations and irrigation requirements of cocoa (Theobroma cacao L.): A review. Exp. Agr. 47(4):653-676.

Cilas, C., R. Machado, and J.C. Motamayor. 2010. Relations between several traits linked to sexual plant reproduction in Theobroma cacao L.: Number of ovules per ovary, number of seeds per pod, and seed weight. Tree Genet. Genomes 6:219-226.

Daymond, A.J., P.J. Tricker, and P. Hadley. 2011. Genotypic variation in photosynthesis in cacao is correlated with stomatal conductance and leaf nitrogen. Biol. Plant. 55(1):99 104.

De Almeida, A.A.F. and R.R. Valle. 2007. Ecophysiology of the cacao tree. Braz. J. Plant Physiol. 19(4):425-448.

Deheuvels, O., G.X. Rousseau, G.S. Quiroga, M.D. Franco, R. Cerda, S.J.V. Mendoza, and E. Somarriba. 2014. Biodiversity is affected by changes in management intensity of cocoabased agroforests. Agrofor. Syst. 88(6):10811099.

De Jong, T.J. and P.G.L. Klinkhamer. 2005. Evolutionary ecology of plant reproductive strate- gies, p. 110-131. Cambridge University Press, Cambridge, UK.

Edwin, J. and W.A. Masters. 2005. Genetic improvement and cocoa yields in Ghana. Expt. Agr. 41(4):491-503.

Falque, M., C. Lesdalons, and A.B. Eskes. 1996. Comparison of two cacao (Theobroma cacao L.) clones for the effect of pollination intensity on fruit set and seed content. Sex. Plant Reprod. 9(4):221-227.

Falque, M., A. Vincent, B.E. Vaissiere, and A.B. Eskes. 1995. Effect of pollination intensity on fruit and seed set in cacao (Theobroma cacao L.). Sex. Plant Reprod. 8(6):354-360.

Forbes, S. and T.D. Northfield. 2016. Increased pollinator habitat enhances cacao fruit set and predator conservation. Ecol. Appl. 27(3):887-899.

Freier, G., F. Vilella, and A.J. Hall. 1984. Withinear pollination synchrony and kernel set in maize. Maydica 29:317-324.

Frimpong, E.A., I. Gordon, P.K. Kwapong, and B. Gemmill-Herren. 2009. Dynamics of cocoa pollination: Tools and applications for surveying and monitoring cocoa pollinators. Intl. J. Trop. Insect Sci. 29(2):62-69.

Gockowski, J. and D. Sonwa. 2011. Cocoa intensification scenarios and their predicted impact on $\mathrm{CO} 2$ emissions, biodiversity conservation, and rural livelihoods in the Guinean rain forest of West Africa. Environ. Mgt. 48(2):307-321.

Goenaga, R., M. Guiltinan, S. Maximova, E. Seguine, and H. Irizarry. 2015. Yield performance and bean quality traits of cacao propagated by grafting and somatic embryo-derived cuttings. HortScience 50:358-362.

Goenaga, R., H. Irizarry, and B. Irish. 2009. TARS series of cacao germplasm selections. HortScience 44:826-827.

Grassini, P., K.M. Eskridge, and K.G. Cassman. 2013. Distinguishing between yield advances and yield plateaus in historical crop production trends. Nat. Commun. 4:2918.

Groeneveld, J.H., T. Tscharntke, G. Moser, and Y. Clough. 2010. Experimental evidence for stronger cacao yield limitation by pollination than by plant resources. Perspect. Plant Ecol. Evol. Syst. 12(3):183-191.

Harris, R.E., R.H. Moll, and C.W. Stuber. 1976 Control and inheritance of prolificacy in maize. Crop Sci. 16(6):843-850.

Hutcheon, W.V. 1977. Water relations and other factors regulating the seasonal periodicity and productivity of cocoa in Ghana, p. 233-244. In: Proceedings of the Fifth International Cocoa Conference.

Johns, N.D. 1999. Conservation in Brazil's chocolate forest: The unlikely persistence of the traditional cocoa agroecosystem. Environ. Mgt. 23(1):31-47.

Kaufmann, T. 1975. Ecology and behavior of cocoa pollinating Ceratopogonidae in Ghana, West Africa. Environ. Entomol. 4(2):347-351.

Lachenaud, P. and G. Mossu. 1985. Comparativestudy of the influence of two methods of management on the production factors of a cocoa farm. Cafe Cacao 29:197-200.

Lafitte, H.R. and G.O. Edmeades. 1995. Stress tolerance in tropical maize is linked to constitutive changes in ear growth characteristics. Crop Sci. 35(3):820-826.

Lass, T. 2004. Balancing cocoa production and consumption, p. 8-15. In: J. Flood and R. Murphy (eds). Cocoa futures: A source book on some important issues facing the cocoa industry. CABI-FEDERACAFE, USDA, Chinchina, Colombia.

Leal, G.A., L.H. Gomes, P. Efraim, F.C.D. Tavares, and A. Figueira. 2008. Fermentation 
of cacao (Theobroma cacao L.) seeds with a hybrid Kluyveromyces marxianus strain improved product quality attributes. FEMS Yeast Res. 8(5):788-798.

Lee, M.T., E.B. Tav, K. Lamin, and M. Saedi. 1993. Catalogue of locally collected clones in Malaysia. Catalogue compiled by the Malaysian Cocoa Board, Sabah, Malaysia. In: C.J. Turnbull and P. Hadley (eds.). International Cocoa Germplasm Database (ICGD). CRA Ltd. ICE Futures Europe. University of Reading, UK. (Online database). 17 Mar. 2017. <http://www.icgd.rdg.ac.uk/ref data.php?refcode $=$ LEE93A\&table=flower $>$.

Lima, L.J.R., M.H. Almeida, M.J. Nout, and M.H. Zwietering. 2011. Theobroma cacao L., "The Food of the Gods": Quality determinants of commercial cocoa beans, with particular reference to the impact of fermentation. Crit. Rev. Food Sci. Nutr. 51(8):731-761.

Motamayor, J.C., K. Mockaitis, J. Schmutz, N. Haiminen, D. Livingstone, O. Cornejo, S.D. Findley, P. Zheng, F. Utro, S. Royaert, C. Saski, J. Jenkins, R. Podicheti, M.X. Zhao, B.E. Scheffler, J.C. Stack, F.A. Feltus, G.M. Mustiga, F. Amores, W. Phillips, J.P. Marelli, G.D. May, H. Shapiro, J.X. Ma, C.D. Bustamante, R.J. Schnell, D. Main, D. Gilbert, L. Parida, and D.N. Kuhn. 2013. The genome sequence of the most widely cultivated cacao type and its use to identify candidate genes regulating pod colour. Genome Biol. 14(6):r53.

Motamayor, J.C., A.M. Risterucci, P.A. Lopez, C.F. Ortiz, A. Moreno, and C. Lanaud. 2002. Cacao domestication I: The origin of the cacao cultivated by the Mayas. Heredity 89:380-386.

Muller, M.W., A.D.S. Pinho, and P.T. Alvim. 1988. Effect of manual pollination on production and the phenology of cacao, p. 275-281. In: 10th International Cocoa Research Conference.

Pinheiro, J., D. Bates, S . DebRoy, D . Sarkar, and R Core Team. 2018. nlme: Linear and nonlinear mixed effects models. R package version 3.1-101.
Pinillos, V. and J. Cuevas. 2008. Artificial pollination in tree crop production, p. 239-236. In: J. Janick (ed.). Horticultural reviews. Vol. 34. University of Almeria, Almeria, Spain.

Posnette, A. 1944. Pollination of cacao in Trinidad. Trop. Agr. 21:115-118.

Ray, D.K., J.S. Gerber, G.K. MacDonald, and P.C. West. 2015. Climate variation explains a third of global crop yield variability. Nat. Commun. 6:5989.

R Core Team. 2013. R: A language and environment for statistical computing. R version 3.2.4. $\mathrm{R}$ Foundation for Statistical Computing, Vienna, Austria.

Rice, R.A. and R. Greenberg. 2000. Cacao cultivation and the conservation of biological diversity. Ambio 29(3):167-173.

Sarquis, J.I., H. Gonzalez, and J.R. Dunlap. 1998. Yield response of two cycles of selection from a semi-prolific early maize (Zea mays L.) population to plant density, sucrose infusion and pollination control. Field Crops Res. 55(12):109-116

Shen, S., L. Zhang, X.G. Liang, X. Zhao, S. Lin, L.H. Qu, Y.P. Liu, Z. Gao, Y.L. Ruan, and S.L. Zhou. 2018. Delayed pollination and low availability of assimilates are major factors causing maize kernel abortion. J. Expt. Bot. 69(7):1599-1613.

Soil Survey Staff. 1999. Soil taxonomy: A basic system of soil classification for making and interpreting soil surveys. 2nd ed. Handbook no. 436. Natural Resources Conservation Service, U.S. Department of Agriculture. U.S. Government Printing Office, Washington, DC.

Stephenson, A.G. 1981. Flower and fruit abortion: Proximate causes and ultimate functions. Annu. Rev. Ecol. Syst. 12:253-279.

Struik, P.C. and T. Makonnen. 1992. Effects of timing, intensity and duration of pollination on kernel set and yield in maize (Zea mays L.) under temperate conditions. Neth. J. Agr. Sci. 40:409-429.

Toledo-Hernandez, M., T.C. Wanger, and T. Tscharntke. 2017. Neglected pollinators: Can enhanced pollination services improve cocoa yields? A review. Agr. Ecosyst. Environ. 247:137-148.

Uma Shaanker, R., K.N. Ganeshaiah, and K.S. Bawa. 1988. Parent-offspring conflict, sibling rivalry and brood size patterns in plants. Annu. Rev. Ecol. Syst. 19:177-205.

Vaast, P. and E. Somarriba. 2014. Trade-offs between crop intensification and ecosystem services: The role of agroforestry in cocoa cultivation. Agrofor. Syst. 88(6):947-956.

Valle, R.R., A.A.F. De Almeida, R.M. De, and O. Leite. 1990. Energy costs of flowering, fruiting, and cherelle wilt in cacao. Tree Physiol. 6(3):329-336

Winder, J.A. 1978. Cocoa flower Diptera: Their identity, pollinating activity and breeding sites. PANS 24(1):5-18.

Wood, G.A.R. and R.A. Lass. 1985. Cocoa. Longman Group Ltd, London, UK.

Young, A.M. 1982. Effects of shade cover and availability of midge breeding sites on pollinating midge populations and fruit set in two cocoa farms. J. Appl. Ecol. 19(1):47-63.

Young, A.M. and D.W. Severson. 1994. Comparative analysis of steam distilled floral oils of cacao cultivars (Theobroma cacao L., Sterculiaceae) and attraction of flying insects: Implications for a Theobroma pollination syndrome. J. Chem. Ecol. 20(10):2687-2703.

Zeileis, A. and T. Hothorn. 2002. Diagnostic checking in regression relationships. R News 2(3):7-10.

Zuidema, P.A., P.A. Leffelaar, W. Gerritsma, L. Wommer, and N.P.R. Anten. 2005. A physiological production model for cocoa (Theobroma cacao): Model presentation, validation and application. Agr. Syst. 84(2):195-225. 


\begin{tabular}{lcccccc}
\hline & \multicolumn{5}{c}{ Pod and bean parameters } \\
\cline { 2 - 6 } Clone & Avg pods/tree/yr & Avg dry bean wt/pod $(\mathrm{g})$ & Avg dry bean wt $(\mathrm{g})$ & Avg no. of beans/100 $\mathrm{g}$ & Pod index $^{\mathrm{y}}$ & Yield $^{\mathrm{x}}(\mathrm{t} / \mathrm{ha} / \mathrm{yr})$ \\
\hline M01 & 57.23 & 58.4 & 1.48 & 67.37 & 17.06 \\
PBC123 & 54.94 & 35 & 0.86 & 115.85 & 3.69 \\
MCC02 & 39.59 & 57.2 & 1.61 & 62.11 & 28.49 \\
BB01 & 42.59 & 46.1 & 1.27 & 78.55 & 17.49 \\
\hline
\end{tabular}

${ }^{\mathrm{z}}$ Values are calculated from several clone evaluation trials between 2009 to 2016. The evaluations involve 100 mature trees per clone, save the MCC02 evaluation which involved 3000 trees. All trees involved in clonal evaluations were propagated by terminal grafting on M01 rootstocks and were cultivated in South Sulawesi, Indonesia.

${ }^{\mathrm{y}}$ Pod index is calculated as the number of pods required to produce $1000 \mathrm{~g}$ dry cacao beans.

${ }^{\mathrm{x}}$ Annual yield per hectare is calculated using a $3 \mathrm{~m} \times 3 \mathrm{~m}$ planting density.

Supplemental Table 2. Analysis of soils at the Mars Cocoa Research Center, Tarengge, South Sulawesi. ${ }^{\text {. }}$

\begin{tabular}{|c|c|c|c|c|c|c|c|c|c|c|c|}
\hline \multicolumn{12}{|c|}{ Soil measurements } \\
\hline$\overline{\mathrm{pH}}$ & OM (\%) & $\mathrm{C}(\%)$ & $\mathrm{N}(\%)$ & Texture & $\mathrm{P}(\mathrm{ppm})$ & $\mathrm{K}\left(\mathrm{cmol} \cdot \mathrm{kg}^{-1}\right)$ & $\mathrm{Ca}\left(\mathrm{cmol} \cdot \mathrm{kg}^{-1}\right)$ & $\mathrm{Mg}\left(\mathrm{cmol} \cdot \mathrm{kg}^{-1}\right)$ & $\mathrm{Na}\left(\mathrm{cmol} \cdot \mathrm{kg}^{-1}\right)$ & CEC $\left(\mathrm{cmol} \cdot \mathrm{kg}^{-1}\right)$ & BS (\%) \\
\hline
\end{tabular}

${ }^{\mathrm{z}}$ Analyses performed in 2016 at laboratories of CIRAD, Montpellier, France [Spaans (2016, unpublished)], and Hasanuddin University (UNHAS), Indonesia (Mars Inc., internal report, unpublished data).

$\mathrm{OM}=$ organic matter; $\mathrm{CEC}=$ cation exchange capacity; $\mathrm{BS}=$ base saturation.

Supplemental Table 3. Nutrient composition of fertilizer applied each month to experimental trees in trial $2 .{ }^{z}$

\begin{tabular}{|c|c|c|c|c|c|c|c|c|c|c|c|c|}
\hline \multirow[b]{2}{*}{ Nutrient $\left(\mathrm{kg} \cdot \mathrm{ha}^{-1}\right)$} & \multicolumn{12}{|c|}{ Month } \\
\hline & Jan. & Feb. & Mar. & Apr. & May & June & July & Aug. & Sept. & Oct. & Nov. & Dec. \\
\hline $\mathrm{P}$ & 29.5 & 18.6 & 18.3 & 9.7 & 11.3 & 29.0 & 27.3 & 18.6 & 18.3 & 9.7 & 11.3 & 28.9 \\
\hline $\mathrm{Mg}$ & 3.3 & 2.5 & 3.7 & 3.8 & 3.4 & 3.3 & 3.3 & 2.5 & 3.7 & 4.2 & 3.4 & 3.7 \\
\hline $\mathrm{S}^{\mathrm{x}}$ & 7.1 & 7.4 & 6.4 & 3.4 & 3.4 & 6.1 & 7.1 & 6.2 & 6.4 & 2.8 & 3.4 & 6.1 \\
\hline $\mathrm{Zn}$ & 0.3 & 0.2 & 0.2 & 0.1 & 0.1 & 0.3 & 0.3 & 0.2 & 0.2 & 0.1 & 0.1 & 0.3 \\
\hline $\mathrm{Mn}$ & 0.4 & 0.2 & 0.4 & 0.5 & 0.4 & 0.4 & 0.4 & 0.2 & 0.4 & 0.5 & 0.4 & 0.4 \\
\hline $\mathrm{Fe}$ & 0.5 & 0.3 & 0.6 & 0.7 & 0.7 & 0.6 & 0.5 & 0.3 & 0.6 & 0.7 & 0.7 & 0.6 \\
\hline
\end{tabular}

${ }^{\mathrm{z}}$ Data obtained from Spaans (2016).

${ }^{\mathrm{y}}$ Source of nutrients includes Mono-Ammonium Phosphate, Potassium nitrate, and Calcium nitrate.

${ }^{\mathrm{x}}$ Source of nutrients includes Magnesium sulfate and Zinc sulfate.

${ }^{\mathrm{w}}$ Source of nutrients is Boric acid. 

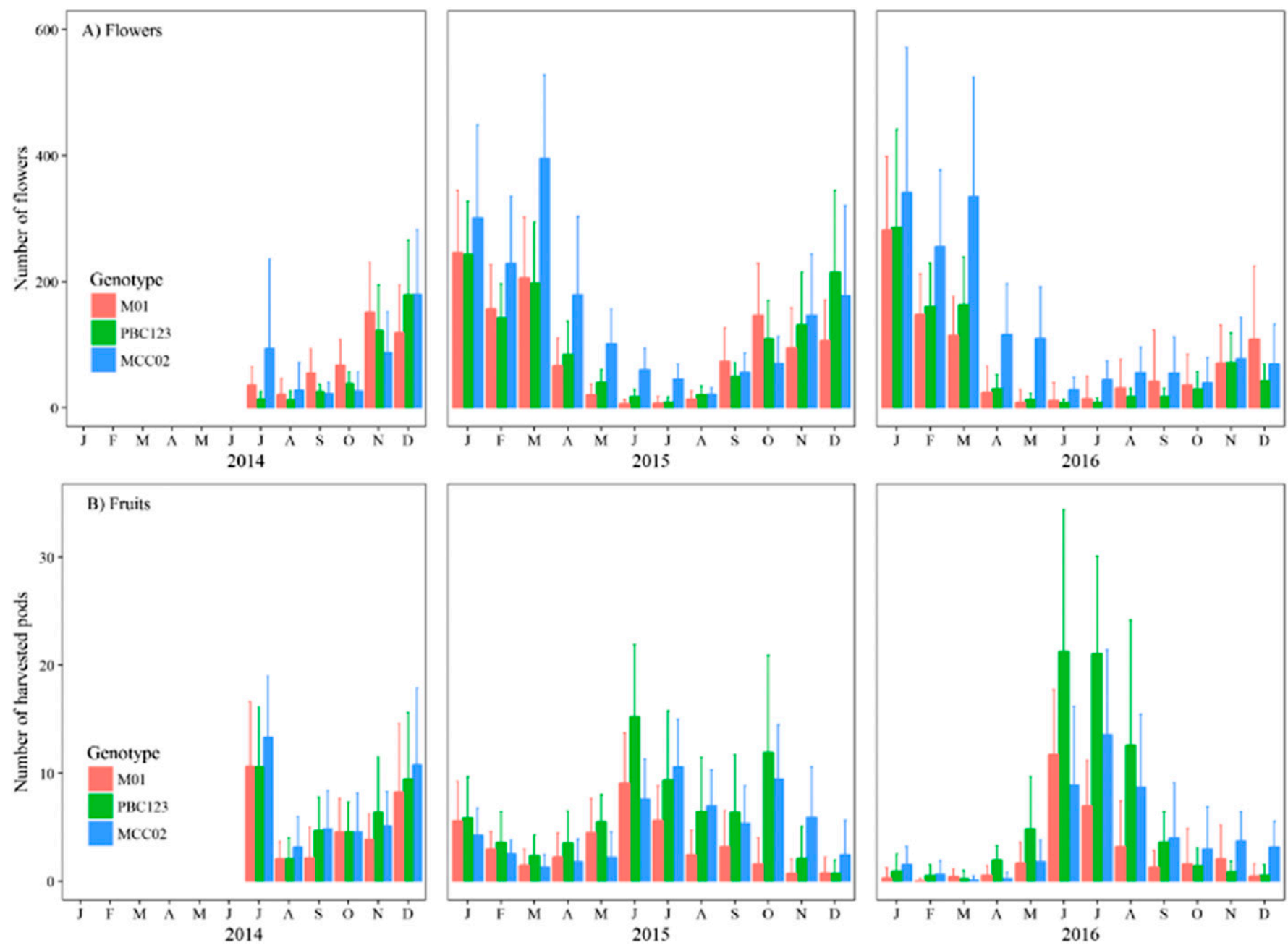

Supplemental Fig. 1. Mean flowers (A) and mean fruit (B) counted per tree for three cacao genotypes between July 2014 and Dec. 2016. The data shown represent mean values of 24 trees/clone (M01, PBC123, MCC02) existing within a clonal cacao field (pollination block I) at the Mars Cocoa Research Center, Tarengge Village, South Sulawesi, Indonesia. (A) Flower data were obtained from the total number of open flowers observed per tree within the dates presented, counted twice per week between 0600 and 1200 HR. (B) Fruit data were obtained from the total number of ripe pods per tree, harvested fortnightly within the dates presented. 